\title{
Análise atual da situação das alunas do curso Bacharelado em Tecnologia da Informação da UFRN
}

\author{
Joicy Daliane Oliveira ${ }^{1}$, Elma Rocha ${ }^{1}$, Thayrone Santos ${ }^{1}$, \\ Soraya Medeiros ${ }^{2}$, Isabel Dillmann Nunes ${ }^{1}$ \\ ${ }^{1}$ Instituto Metrópole Digital (IMD), Universidade Federal do Rio Grande do Norte \\ (UFRN) - Natal- RN - Brasil \\ ${ }^{2}$ Centro de Ensino Superior do Seridó (CERES), Universidade Federal do Rio Grande \\ do Norte (UFRN) - Caicó - RN - Brasil \\ \{joiicyoliv, thayronedds, soraya.roberta.js\}@gmail.com, \\ elmasantos94@hotmail.com, bel@imd.ufrn.br
}

\begin{abstract}
This article aims to show the current profile of the students in the Bachelor of Information Technology course at the Metrópole Digital Institute of UFRN. Based on these data the Extension Project "Women in IT" was proposed with the purpose of attracting the girls of the secondary and fundamental education, as well as to encourage the permanence of the girls in the course.
\end{abstract}

Resumo. Este artigo tem o objetivo de mostrar o perfil atual das alunas no curso de Bacharelado em Tecnologia da Informação do Instituto Metrópole Digital da UFRN. A partir desses dados o Projeto de Extensão "Mulheres na TI" foi proposto com o propósito de atrair as meninas do ensino médio e fundamental, como também fomentar a permanência das meninas no curso.

\section{Introdução}

Ao longo da história, as mulheres tiveram papel importante para o desenvolvimento da área da Computação, tal como Ada Lovelace e Margareth Hamilton. Contudo, segundo dados da Pesquisa Nacional por Amostra de Domicílios- PNAD- em 2013, apenas 17\% dos profissionais de TI no Brasil eram mulheres, ganhando $30 \%$ a menos que homens nos mesmos cargos, com mesma escolaridade. Além disso, de acordo com o estudo realizado pelo Censo da Educação Superior INEP (2015), em 1991, as mulheres totalizavam 34,9\% dos discentes que estavam matriculados em cursos da área de Computação e correlatas, porém, em 2013, o valor caiu para 15,53\%. Essa diminuição no número de mulheres, fortalece o crescimento da disparidade entre mulheres e homens em cursos da área de exatas.

Pensando nessa perspectiva, durante a disciplina "Tópicos Especiais em Informática Educacional 'C' (Análise de Dados Educacionais)" do curso Bacharelado em Tecnologia da Informação (BTI-UFRN), foi feito um levantamento de dados sobre o percentual de alunas no referido curso em relação aos meninos e iniciou-se o questionamento sobre quais seriam os fatores que estariam influenciando na matrícula, permanência e conclusão dessas alunas durante o curso. Para responder a tal problemática, o presente estudo analisa a situação atual das discentes do BTI. Para 
tanto, foram utilizados os dados disponíveis no Portal de Dados Abertos UFRN ${ }^{1}$, referentes aos discentes do Bacharelado em Tecnologia da Informação, a partir do semestre 2013.1 até 2017.1.

\section{Situação das mulheres no BTI-UFRN}

O curso de Bacharelado em Tecnologia da Informação teve início no ano de 2013, vinculado institucionalmente ao Instituto Metrópole Digital (IMD), Unidade Acadêmica Especializada que dá suporte às atividades acadêmicas de ensino, pesquisa e extensão. Desde seu início, o curso apresenta corpo discente majoritariamente masculino. Com uma média de 300 alunos ingressantes por ano, a quantidade de mulheres que optam pelo curso é visivelmente baixa. O semestre com o maior número de mulheres foi 2015.2 , onde cerca de $20 \%$ passaram a integrar o corpo discente. O mais baixo foi 2016.2: apenas 4\% do total eram mulheres. Ao todo, de 2013 até o primeiro semestre de 2017, 1749 alunos vincularam-se ao BTI e, desse número, foram aproximadamente 170 do sexo feminino, como mostra a Figura 1.

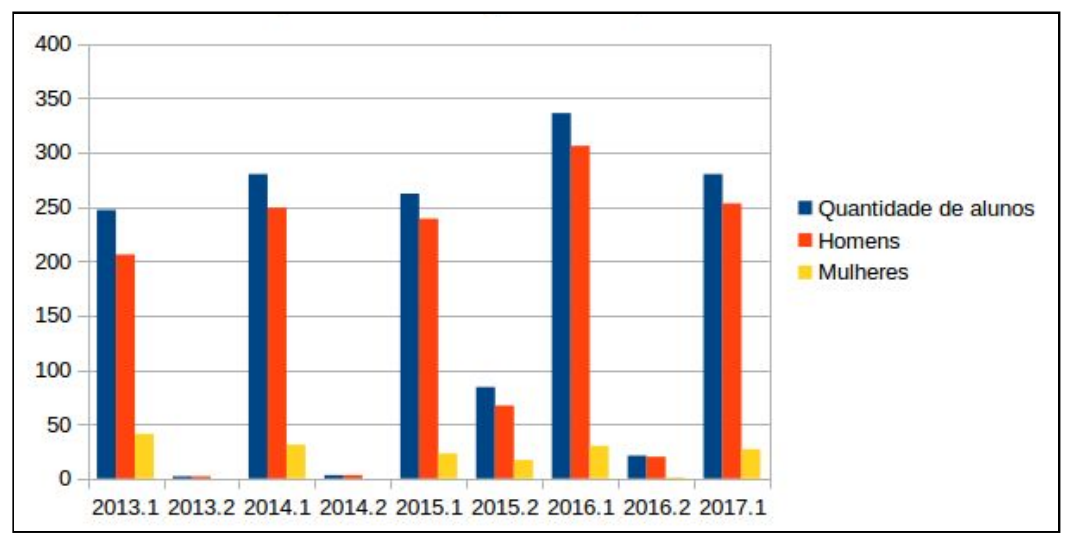

Figura 1. Quantidade de ingressantes por semestre.

Os dados utilizados nesta análise foram obtidos no Portal de Dados Abertos da UFRN. O portal tem o objetivo disponibilizar para toda a comunidade as informações públicas da instituição, permitindo a pesquisa, o desenvolvimento de aplicativos e ações. Analisando o perfil das mulheres que chegam até o curso, é possível notar que a maior parte delas vive em situação de vantagem social.

Para melhor entendimento do perfil das mulheres no BTI, foram obtidos os dados referente a etnia de cada uma. A minoria das alunas são negras ou remanescentes de quilombo, enquanto a grande maioria é composta por pardas ou brancas (Figura 2). Dentre as ingressantes que vivem na capital do estado, predominam as oriundas de zona privilegiada (53\% moram na zona sul da cidade), onde encontra-se a maioria da população de classe média-alta (Figura 3). Também há poucas que fazem parte do sistema de cotas: do total de alunas ingressantes, cerca de $29 \%$ eram cotistas. Tais informações podem ser vistas na Figura 4.

Em meio aos alarmantes índices da pouca participação feminina, existe o problema da não permanência no curso. Os índices de evasão são altos tanto para homens quanto para mulheres. Os alunos de determinado semestre que chegam à

\footnotetext{
1 "Dados Abertos da UFRN." http://dados.ufrn.br/. Acessado em 5 abr. 2018.
} 
conclusão do curso não representam nem $50 \%$ da quantidade que ingressou. Como consequência, aproximadamente $19 \%$ dos concluintes são mulheres, como visto na Figura 5.

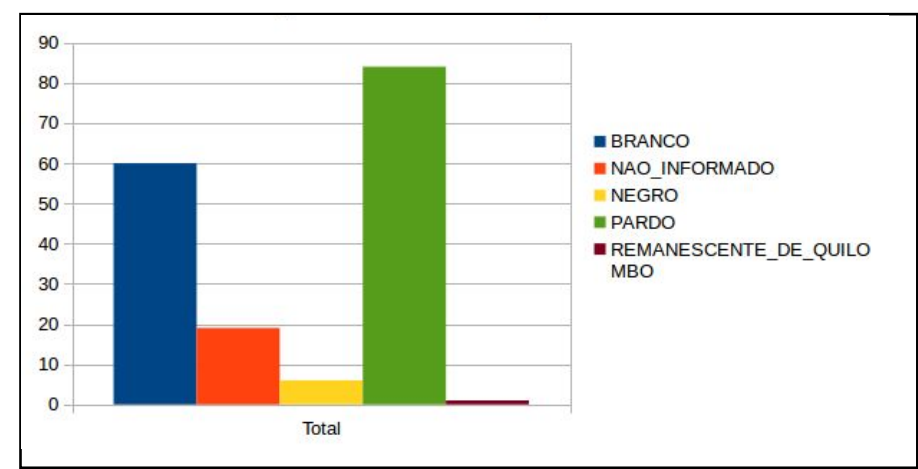

Figura 2. Total de mulheres ingressantes por identificação étnica.

Tais dados informam a baixa entrada de alunas no curso e, ainda, a grande desistência das que ingressaram. Esse quadro traz a preocupação de não somente mostrar para meninas do ensino fundamental e médio que elas são capazes de atuar na área de TI, como também são capazes de permanecer no curso, mesmo estando em situação de minoria e sentindo-se desmotivadas e desencorajadas, até mesmo, por colegas e professores.

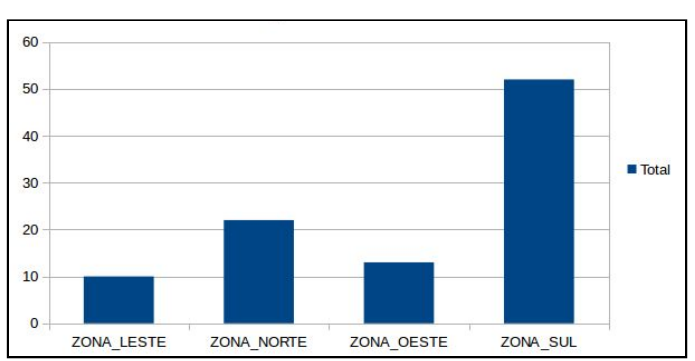

Figura 3. Total de mulheres ingressantes por zonas da cidade de Natal-RN.

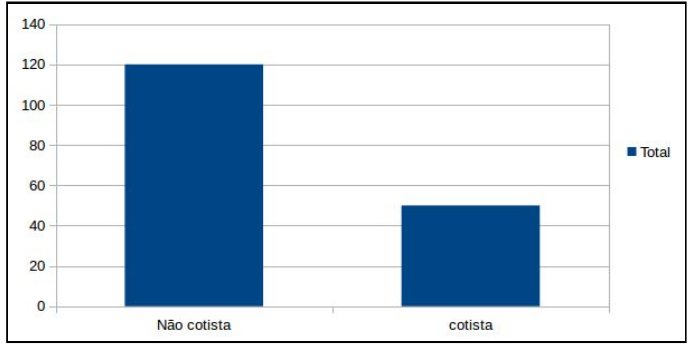

Figura 4. Total de mulheres ingressantes cotistas ou não cotistas

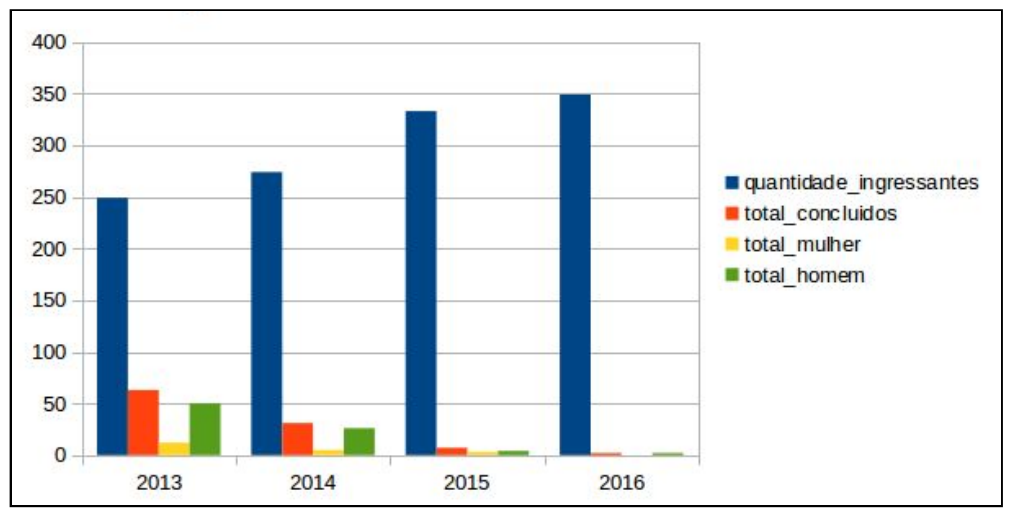

Figura 5. Comparativo de conclusão do curso.

\section{O que está sendo feito}

No intuito de promover a permanência das alunas do curso e disseminar a área foi criado em 2018 um Projeto de Extensão denominado ${ }^{M}$ Mulheres na TI ${ }^{\sim}$, com participação de professoras e professores, alunas e alunos. O grupo tem como foco tanto 
a atuação no ensino médio e fundamental para promover a área de tecnologia, mas também em fazer com que as mulheres do Curso de Bacharelado em TI permaneçam e sejam valorizadas como estudantes e futuras profissionais.

No ano de 2018 já foram realizadas atividades que divulgam o projeto e, principalmente, que há um grupo dentro do IMD que luta e promove a valorização feminina. Entre as atividades realizadas estão: (1) roda de conversa, na semana do dia internacional da mulher, sobre a atuação da mulher na tecnologia. Nesta ação, que chamou atenção de várias pessoas da universidade que estavam no IMD, depoimentos de meninas do curso foram realizados. Tais depoimentos mostram como é necessário atuarmos na construção de meios para o fortalecimento do universo feminino dentro do curso, como mostra a Figura 6 (2) Na mesma semana, um workshop de Game Design foi elaborado com o objetivo de mostrar que existe representatividade feminina no mundo dos jogos e ensinar os conceitos básicos de construção de um jogo. Nesta atividade, voltada somente para as mulheres, foi possível visualizar o grande interesse das meninas na área de jogos e assim sua promoção (Figura 7). (3) Também foi realizado um mini curso de introdução à programação com Python para iniciantes da área de TI, para que haja maior engajamento tecnológico entre as alunas.

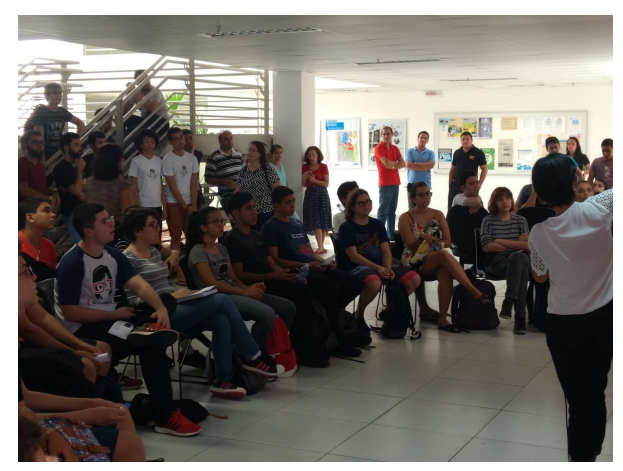

Figura 6. Roda de Conversa.

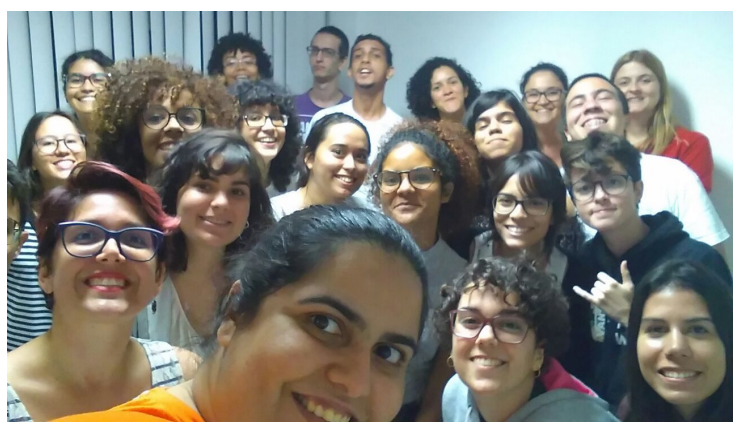

Figura 7. Oficina de Game Design.

Outras ações estão sendo planejadas para o ano de 2018. Um momento será a atuação nas escolas de ensino médio para o ensino de programação e introdução da área de tecnologia para as meninas. Em outra frente, ações voltadas para as mulheres já no ensino superior serão realizadas, tais como ensino de programação, oficinas e hackathons, palestras e rodas de conversa.

\section{Considerações finais}

Esse trabalho teve como objetivo analisar a situação atual das mulheres do BTI-UFRN, de forma a compreender como está configurada essa minoria no corpo discente. A partir dos dados levantados, foi possível confirmar que a divergência de quantidade de mulheres em relação à homens no curso ainda é grande, assim como a evasão de discentes. Um outro fato importante de ser observado é a questão social das alunas, onde quase não há presença de cotistas e periféricas. Apontamos ações que estão sendo feitas para reverter o quadro atual do corpo discente, que buscam apoiar, encorajar e manter as alunas presentes no curso, bem como inspirar futuras ingressantes e auxiliá-las a ter êxito na área. Espera-se que tais ações tenham impacto positivo no 
corpo acadêmico e que, em um futuro próximo, os índices mostram maior diversidade de alunos e maior êxito ao fim do curso.

\section{Referências Bibliográficas}

INEP (2015) "Resumo Técnico da Educação Superior 2013", Diretoria de Estatísticas Educacionais DEED, Instituto Nacional de Estudos e Pesquisas Educacionais Anísio Teixeira, Brasília-DF, 82 p.

SBC - Educação Superior em Computação - Estatísticas - 2014 Disponível em http://www.sbc.org.br/documentos-da-sbc/summary/133-estatisticas/1007-estatisticas -daeducacao-superior-2014. Acessado em 01 de junho de 2016. (http://ebooks.pucrs.br/edipucrs/anais/csbc/assets/2016/wit/24.pdf)

Programaria (2016). Ser mulher em tech. Site Programaria. Disponível em $<$ https://www.programaria.org/sermulheremtech/>. Acessado em: 05-04-2018. 